\title{
Rotary ultrasonic machining of CFRP: A comparison with grinding
}

\author{
F.D. Ning ${ }^{1}$, W.L. Cong ${ }^{1 *}$, Z.J. Pei ${ }^{2}$, and C. Treadwell ${ }^{3}$ \\ ${ }^{1}$ Department of Industrial Engineering, Texas Tech University, Lubbock, TX, USA \\ ${ }^{2}$ Department of Industrial and Manufacturing Systems Engineering, Kansas State University, Manhattan, KS, USA \\ ${ }^{3}$ Sonic-Mill, 7500 Bluewater Road NW, Albuquerque, NM, USA
}

\begin{abstract}
Carbon fiber reinforced plastic (CFRP) composites have been intensively used in various industries due to their superior properties. In aircraft and aerospace industry, a large number of holes are required to be drilled into CFRP components at final stage for aircraft assembling. There are two major types of methods for hole making of CFRP composites in industry, twist drilling and its derived multi-points machining methods, and grinding and its related methods. The first type of methods are commonly used in hole making of CFRP composites. However, in recent years, rotary ultrasonic machining (RUM), a hybrid machining process combining ultrasonic machining and grinding, has also been successfully used in drilling of CFRP composites. It has been shown that RUM is superior to twist drilling in many aspects. However, there are no reported investigations on comparisons between RUM and grinding in drilling of CFRP. In this paper, these two drilling methods are compared in five aspects, including cutting force, torque, surface roughness, hole diameter, and material removal rate.
\end{abstract}

\section{Keywords}

Rotary ultrasonic machining (RUM), Carbon fiber reinforced plastic (CFRP) composite, Grinding, Drilling.

*Corresponding author. Tel.:+1 806834 6178; fax: +1 8067423411 .

E-mail address: weilong.cong@ttu.edu. 


\section{Introduction}

\subsection{Properties and applications of CFRP composites}

Carbon fiber reinforced plastic (CFRP) composites consist of two materials: carbon fibers and polymer. Within CFRP composites, carbon fibers are surrounded by the polymer matrix. The carbon fibers are used to support the load, while the polymer matrix is used to bind and protect the fibers and transfer the load to the reinforcing fibers [Chung, 2010; Gay et al., 2003; Kinet et al., 2014].

CFRP composites have a variety of attractive properties, including low density (providing light-weight engineering solutions); high stiffness-to-weight ratio; excellent fatigue and wear resistance; high dimensional stability; and low friction coefficient, thermal expansion, electrical conductivity [Tong et al., 2002; Chung, 2010; Strong, 2008; Park et al., 1995; Davim and Reis, 2003; Mallick, 1997].

Due to these superior properties, more and more CFRP composites have been widely used in many different applications, such as aerospace and commercial aircraft, automobile, sports goods, robot arms, bridges, chemical containers, and fishing rods [Sadat, 1995; Guu et al., 2001; Mazumdar, 2001]. Especially in aerospace and commercial aircraft industry, the usage of CFRP composites grows remarkably. For instance, in Boeing 787, the newest generation of commercial aircraft in the Boeing company, about $50 \%$ of the materials in weight are composites, leading to weight savings of 20\% [Quilter, 2001; Boeing Co. Web]. Besides, as aircraft is engaged in corrosive environments, composites will not be easily subject to fatigue and corrosion damage due to their good fatigue and corrosion resistance, resulting in saving on maintenance costs [Online, 2012]. 


\subsection{Drilling in CFRP composites}

In CFRP composites applications, hole making is an important machining operation for assembly purposes. For example, a large number of holes need to be drilled for assembly of Boeing 787 aircraft [Boeing Co. Web]. Twist drilling, milling and their derived methods were commonly used in drilling of composites [Ramulu et al., 2001; Tsao and Hocheng, 2004; Abrate and Walton, 1992], but they had many drawbacks including high tool wear (short tool life), bad surface roughness, severe delamination, low hole accuracy, etc. To reduce or eliminate these problems, abrasive machining methods (grinding [Soo et al., 2012] and abrasive water jet machining [Kalla et al., 2012]), vibration assisted grinding [Wang et al., 2004], hybrid machining methods (rotary ultrasonic machining (RUM) [Li et al., 2007; Cong et al., 2011]), and laser assisted drilling [Stock et al., 2012]) were also used in hole making of CFRP composite materials. However, abrasive water jet machining had high consumable cost (slurry), and laser assisted twisting drilling consumed high energy. In addition, the hole accuracy of both methods was limited due to the differences between hole entrance and exit in abrasive water jet machining and heat affected zone in laser assisted drilling. It was reported that RUM of CFRP led to small cutting force, surface roughness, delamination, tool wear, etc. [Cong et al., 2012a], and grinding in drilling of CFRP had limited tool life and high abrasive wear of the tool [Biermann and Feldhoff, 2012]. However, there are no reported investigations on comparisons between RUM and grinding in drilling of CFRP.

RUM, a hybrid machining process, is a grinding process assisted with ultrasonic vibration, as illustrated in Figure 1. Compared with grinding, using RUM would not require significantly higher energy by analyzing energy consumption during RUM of CFRP composites [Cong et al., 2012b]. The cutting tool is a core drill with metal-bonded abrasives. During RUM, the rotating 
tool vibrates ultrasonically (typically $20 \mathrm{kHz}$ ) in the tool axis direction and is fed towards the workpiece. Coolant is pumped through the center core of the cutting tool to wash out the swarf and prevent the cutting zone from overheating.

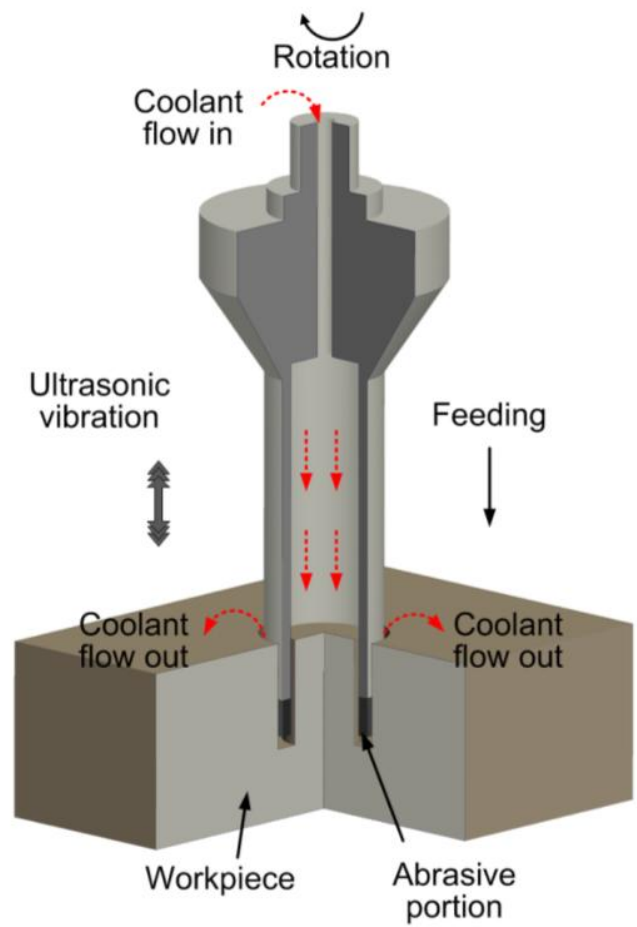

Figure 1. Illustration of rotary ultrasonic machining.

Comparisons between two types of drilling methods (RUM and grinding) are conducted for the first time. This paper makes comparisons in five aspects (cutting force, torque, surface roughness, hole diameter, and material removal rate). There are four sections in this paper. Following this introduction section are experimental conditions and measurement procedures, experimental results and discussions, and conclusions.

\section{Experimental conditions and measurement procedures}

\subsection{Properties of workpiece material}

The CFRP workpiece used in this experiment, as illustrated in Figure 2, consisted of plain woven 
structured carbon fibers and epoxy resin matrix. The carbon fiber yarn in the woven structure had an orientation of $0 / 90$ degrees, a thickness of $0.2 \mathrm{~mm}$, and a width of $2.5 \mathrm{~mm}$. The workpiece contained 42 layers of carbon fibers and had the size of $200 \mathrm{~mm} \times 150 \mathrm{~mm} \times 16 \mathrm{~mm}$. Specific properties of the workpiece material are listed in Table 1.

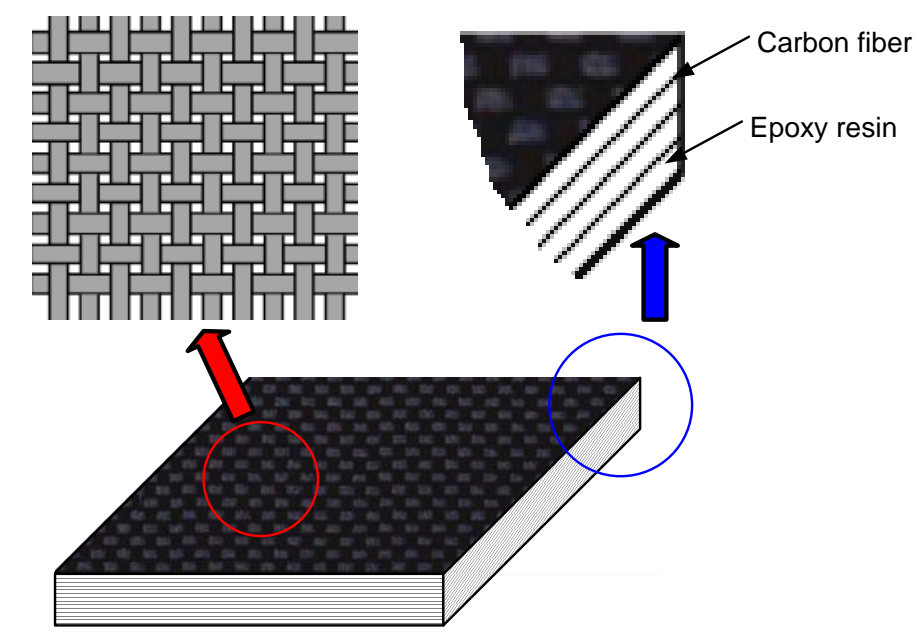

Figure 2. Illustration of Fiber structures in CFRP.

Table 1. Properties of workpiece material.

\begin{tabular}{lll}
\hline Property & Unit & Value \\
\hline Density of CFRP & $\mathrm{kg} / \mathrm{m}^{3}$ & 1550 \\
Hardness (Rockwell) & $\mathrm{HRB}$ & $70-75$ \\
Poisson's Ratio $\left(\mathrm{v}_{12}\right)$ & - & 0.34 \\
Poisson's Ratio $\left(\mathrm{v}_{13}\right)$ & - & 0.34 \\
Poisson's Ratio $\left(\mathrm{v}_{23}\right)$ & - & 0.42 \\
Longitudinal Young's modulus $\left(\mathrm{E}_{1}\right)$ & $\mathrm{GPa}$ & 136 \\
Transverse Young's modulus $\left(\mathrm{E}_{\mathrm{t}}\right)$ & $\mathrm{GPa}$ & 10.5 \\
In-plane shear modulus $\left(\mathrm{G}_{12}\right)$ & $\mathrm{GPa}$ & 3.76 \\
\hline Density of epoxy matrix & $\mathrm{kg} / \mathrm{m}^{3}$ & 1200 \\
Poisson's ratio of epoxy matrix & - & 0.4 \\
Young's modulus of epoxy matrix & $\mathrm{GPa}$ & 4.5 \\
Fracture toughness of epoxy matrix $\left(\right.$ Energy/G $\left._{\mathrm{c}}\right)$ & $\mathrm{J} / \mathrm{m}^{2}$ & 500 \\
\hline Density of carbon fiber & $\mathrm{kg} / \mathrm{m}^{3}$ & 1800 \\
Poisson's ratio of carbon fiber & - & 0.3 \\
Young's modulus of carbon fiber & $\mathrm{GPa}$ & 230 \\
Fracture toughness of carbon $($ Energy/G & $\mathrm{J} / \mathrm{m}^{2}$ & 2 \\
\hline
\end{tabular}




\subsection{Experimental set-up and conditions}

The experiments were performed on a rotary ultrasonic machine (Series 10, Sonic-Mill, Albuquerque, New Mexico, USA). The RUM experimental set-up included an ultrasonic spindle system, a data acquisition system, and a cooling system, as illustrated in Figure 3.

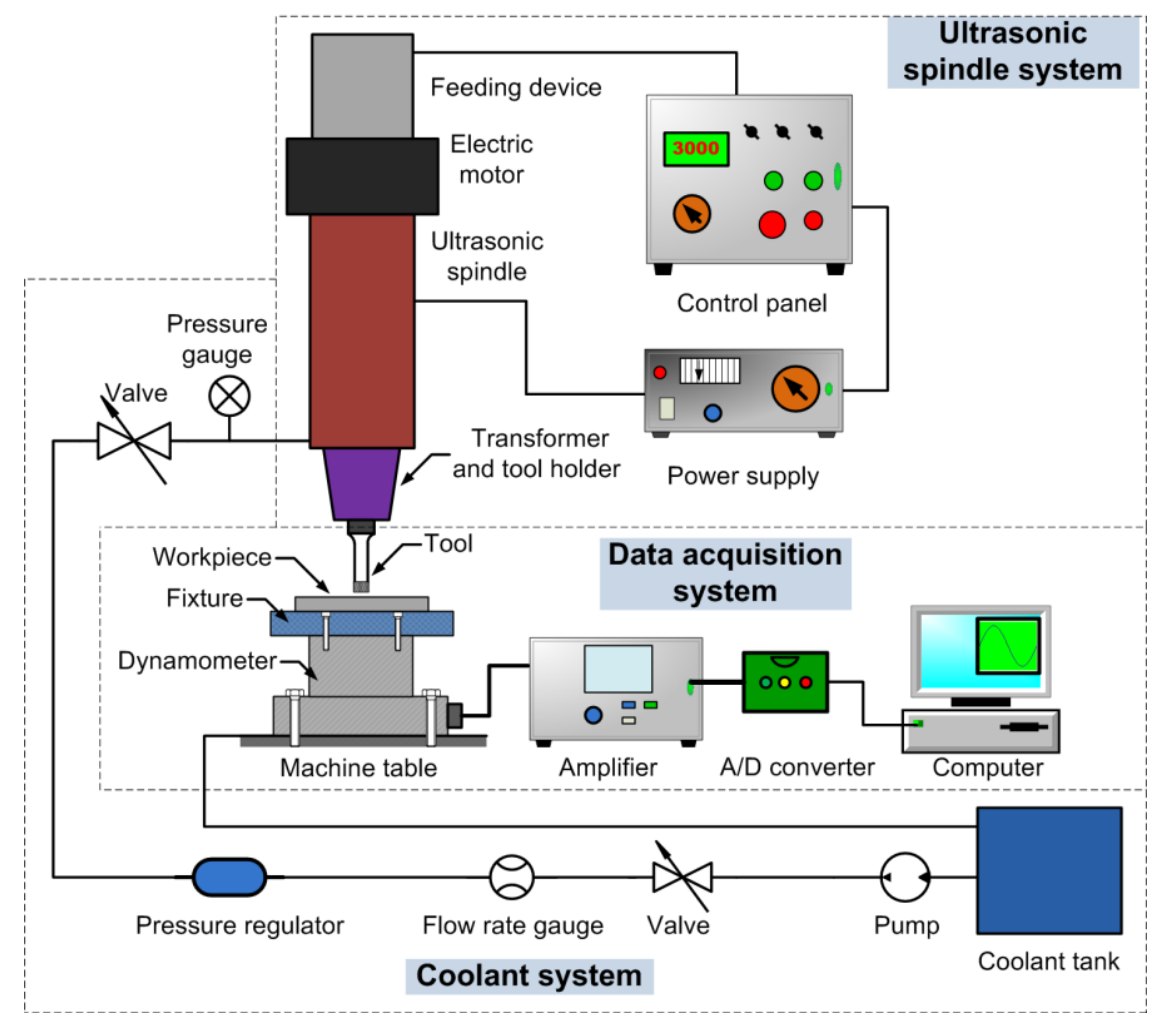

Figure 3. Rotary ultrasonic machining (RUM) experimental set-up.

The ultrasonic spindle system was mainly comprised of an ultrasonic spindle, a power supply, and a motor speed controller. The power supply was used to convert conventional $(60 \mathrm{~Hz})$ electrical supply to high-frequency $(20 \mathrm{kHz})$ electrical energy which was provided to a piezoelectric converter. The converter was located inside the ultrasonic spindle and could convert high-frequency electrical energy into high-frequency mechanical vibration. The ultrasonic vibration generated by the converter was amplified and transmitted to the cutting tool which was attached to the spindle, making the tool to vibrate vertical to the tool face at a high frequency. 
The amplitude of ultrasonic vibration was adjusted under different settings of output control of the power supply. The rotational motion of the tool was provided by the motor attached atop the ultrasonic spindle and various speeds were obtained by changing the motor speed controller. The data acquisition system mainly consisted of a dynamometer (Model 9272, Kistler Inc., Switzerland), a charge amplifier (Model 5070A, Kistler Inc., Switzerland), and an A/D converter. The data acquisition system in Figure 3 was involved in measuring the cutting force and torque during RUM of CFRP composites. The detailed information will be provided in Section 2.3. The cooling system was comprised of a pump, a coolant tank, a pressure regulator, flow rate and pressure gauges, and valves. Coolant was supplied to the spindle and the interface of machining.

The cutting tool used in both RUM and grinding was a metal-bonded diamond core drill (NBR Diamond tool corp., LaGrangeville, NY, USA), as shown in Figure 4. The detailed tool parameters are listed in Table 2.

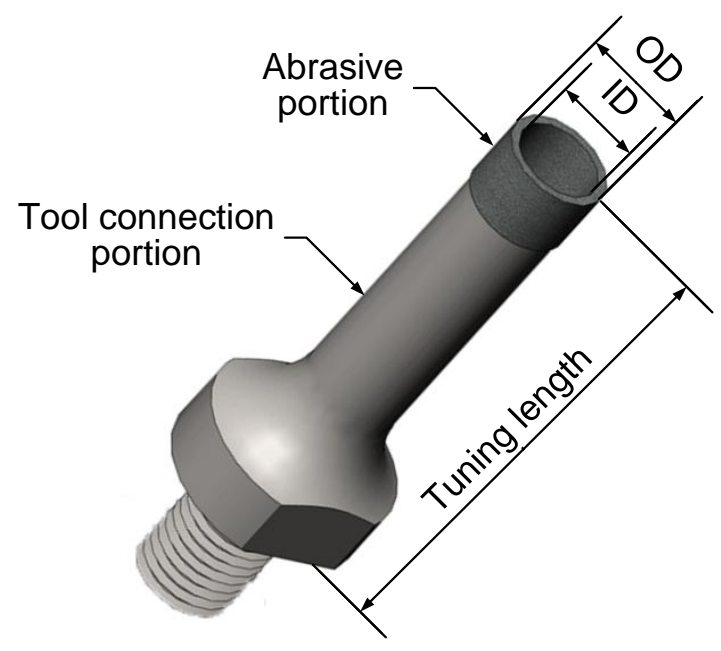

Figure 4. Illustration of the tool used in both RUM and grinding.

The power and frequency of ultrasonic vibration in RUM were fixed at $40 \%(13.5 \mu \mathrm{m}$ in amplitude for the tool used in this experiment) and $20 \mathrm{kHz}$, respectively, and there was no such vibration in grinding. Effects of tool rotation speed and feed rate on five output variables were 
investigated using both drilling methods, as shown in Table 3. The ranges of feed rate and tool rotation speed were chosen according to the experience from the authors' preliminary experiments as well as the guidance from the RUM machine manufacturer, Sonic-Mill Inc. To make comparisons between RUM and grinding, the feed rate and tool rotation speed were kept the same. Four holes were drilled under each combination of input variables.

Table 2. Tool parameters.

\begin{tabular}{lll}
\hline Parameter & Unit & Value \\
\hline Outer diameter & $\mathrm{mm}$ & 9.6 \\
Inner diameter & $\mathrm{mm}$ & 7.8 \\
Tuning length & $\mathrm{mm}$ & 44.5 \\
Abrasive material & & Diamond \\
Grit size & mesh \# & $60 / 80$ \\
Grain concentration & & 100 \\
Number of slots & & 0 \\
Bond & & $\mathrm{B}$ (metal) \\
\hline
\end{tabular}

Table 3. Machining conditions.

\begin{tabular}{ll}
\hline Feed rate $(\mathbf{m m} / \mathbf{s})$ & Tool rotation speed $(\mathbf{r p m})$ \\
\hline $0.1,0.2,0.3,0.4$ & 3000 \\
$0.5,0.6,0.7,0.8$ & \\
\hline 0.5 & $\begin{array}{l}1000,2000,3000 \\
4000,5000\end{array}$ \\
\hline
\end{tabular}

\subsection{Measurement procedures for output variables}

The dynamometer was used for measuring cutting force in the axial direction and torque, and the electrical signals from it were amplified by the charge amplifier. Then the A/D converter transformed the electrical signals into digital signals, which would be collected by a data acquisition card (PC-CARD-DAS16/16, Measurement Computing Corporation, Norton, MA, USA) with the help of DynoWare software package (Type 2815A, Kistler Inc., Switzerland) on a computer. The sampling rate was $20 \mathrm{~Hz}$ during all experiments under the condition of 10 points 
being read per scan, where each data point would be an average value of 10 points, so that a large amount of data points could be avoided. As the maximum sampling rate of dynamometer system $(6000 \mathrm{~Hz})$ was much lower than the frequency of ultrasonic vibration, the detailed cutting force and torque affected by each cycle of ultrasonic vibration would not be explored [Feng et al., 2012; Liu et al., 2012].

The measured cutting force fluctuated with time within a certain range. A typical curve of cutting force signal in time domain during RUM of CFRP is shown in Figure 5. Cutting force for drilling each hole was represented by the maximum cutting force value (Fz) [Cong et al., 2014a; Cong et al., 2013]. The maximum value of cutting force was of the major concern since such instantaneous value would determine the maximum stress in the workpiece and influence the drilling operation performance, including the part accuracy, surface quality, tool life, etc.. The maximum value of cutting force was defined as the median of five values (two before, two after, and present data point) with the applied smooth function. Similarly, torque for drilling each hole was represented by the maximum torque value obtained by using the same principle.

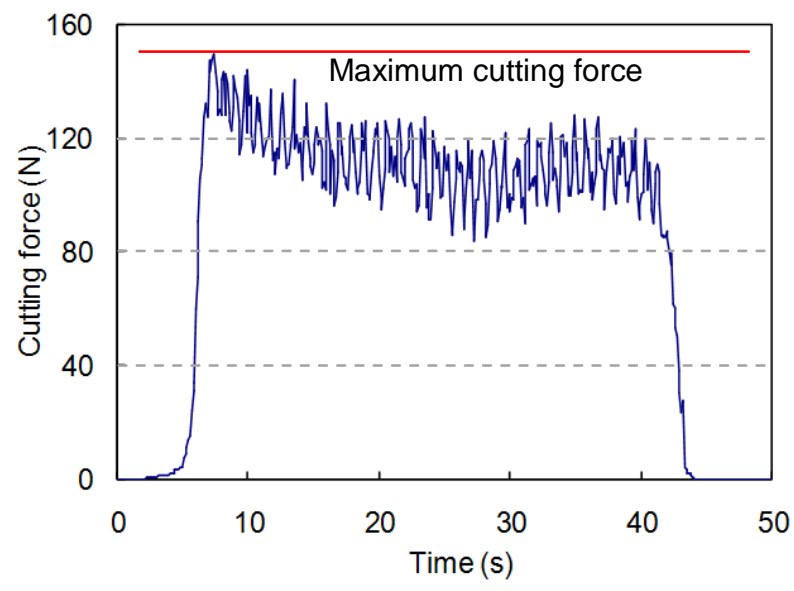

Figure 5. Typical relationship between cutting force and time (in RUM).

The machined hole and machined rod (material removed by RUM tool) in the two drilling 
methods were illustrated in Figure 6. A surface profilometer (Surftest-402, Mitutoyo Corporation, Kanagawa, Japan) was used to measure surface roughness on the machined surface of each hole. The tested range and cut-off length were set as $4 \mathrm{~mm}$ and $0.8 \mathrm{~mm}$, respectively. In this paper, average surface roughness $\mathrm{Ra}$ was chosen to evaluate the machined hole surfaces. The measurement of $\mathrm{Ra}$ started at a location near the hole entrance and moved along the axial direction of the hole. Four measurements were performed with $90^{\circ}$ between two adjacent measurements. Each measurement was repeated twice, leading to eight Ra values in total for each hole. The average of these eight values was used as the Ra value for each hole.

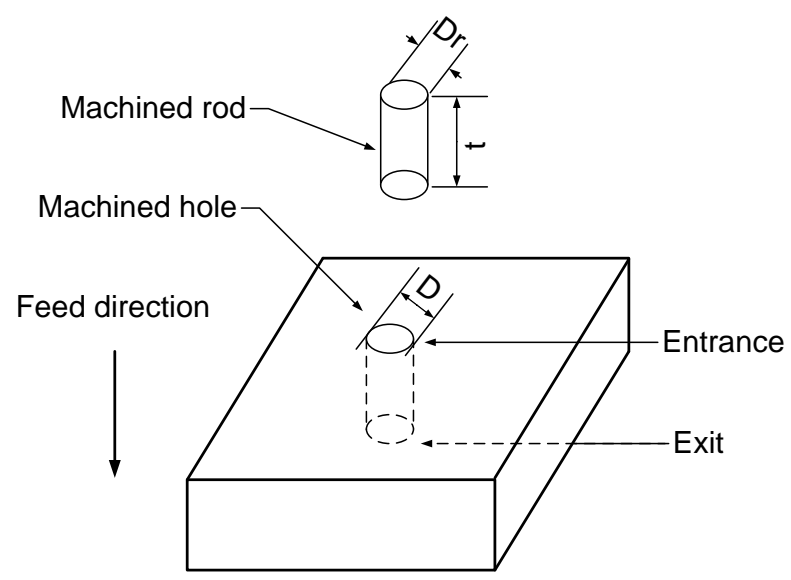

Figure 6. Illustration of the machined hole and rod.

The diameter of machined hole was used to evaluate the hole quality. Hole diameter (D) was measured by a Vernier caliper (model IP-65, Mitutoyo Corp., Kanagawa, Japan). The measurements were conducted along two directions perpendicular to each other with each measurement repeated twice. Therefore, there were four values of hole diameter for each hole and the average of these four values was used to represent the hole diameter. The optical microscope (TS100, Nikron Corp., Tokyo, Japan) was also used to measure the hole diameter with the function of circular measurement to validate the measuring accuracy of the Vernier caliper. 
Material removal rate (MRR) was calculated as the volume of removed material in form of cutting chips divided by machining time. It can be expressed by the following equation:

$$
M R R=\frac{\pi \cdot\left[(D / 2)^{2}-\left(D_{r} / 2\right)^{2}\right] \cdot h}{T}
$$

where, $D$ is the diameter of machined hole, $h$ is the thickness of workpiece, $T$ is the time for drilling the hole, and $D_{r}$ is the diameter of machined rod, which was also measured by the Vernier caliper. Such machined rod could not be considered as the removed material in this equation, since it was not removed in form of cutting chips.

\section{Experimental results and discussions}

All the data points in Figures $7-16$ are plotted by the average values from four drilled holes under the same condition. The maximum and minimum values among four holes were reflected in error bars.

\subsection{Effects on cutting force}

A comparison of cutting force between RUM and grinding when tool rotation speed changed is shown in Figure 7. With the increase of tool rotation speed from 1000 to $5000 \mathrm{rpm}$, cutting force decreased in both RUM and grinding. In RUM, as feed rate was fixed, MRR (as well as the material removal volume by one abrasive particle $V_{1}$ ) would not change. Increase in tool rotation speed resulted in increase of effective cutting distance. To keep the material removed volume $V_{1}$ unchanged, the indentation depth should decrease. In this case, effective cutting time $\Delta t$ and max impact force $F_{1}$ decreased accordingly [Cong et al., 2014b]. In addition, cutting force can be calculated by [Pei et al., 1995]:

where,

$$
F=\Delta t f F_{i}=n \Delta t f F_{1}
$$


$n$ is the number of active abrasive grains on the end face of cutting tool;

$f$ is the frequency of ultrasonic vibration;

$F_{i}$ is the interaction force.

Based on Equation 2, the number of active abrasive grains $n$ and ultrasonic frequency $f$ were constant, therefore, cutting force would decrease with the increase of tool rotation speed.

In grinding, with the increase of tool rotation speed, the penetration depth of the diamond grain into the workpiece material decreased. The penetration depth was associated with interaction force which determined the cutting force. The interaction force generated between diamond grains on the drill end surface and the workpiece material decreased with the decrease of penetration depth, leading to the decreased cutting force accordingly.

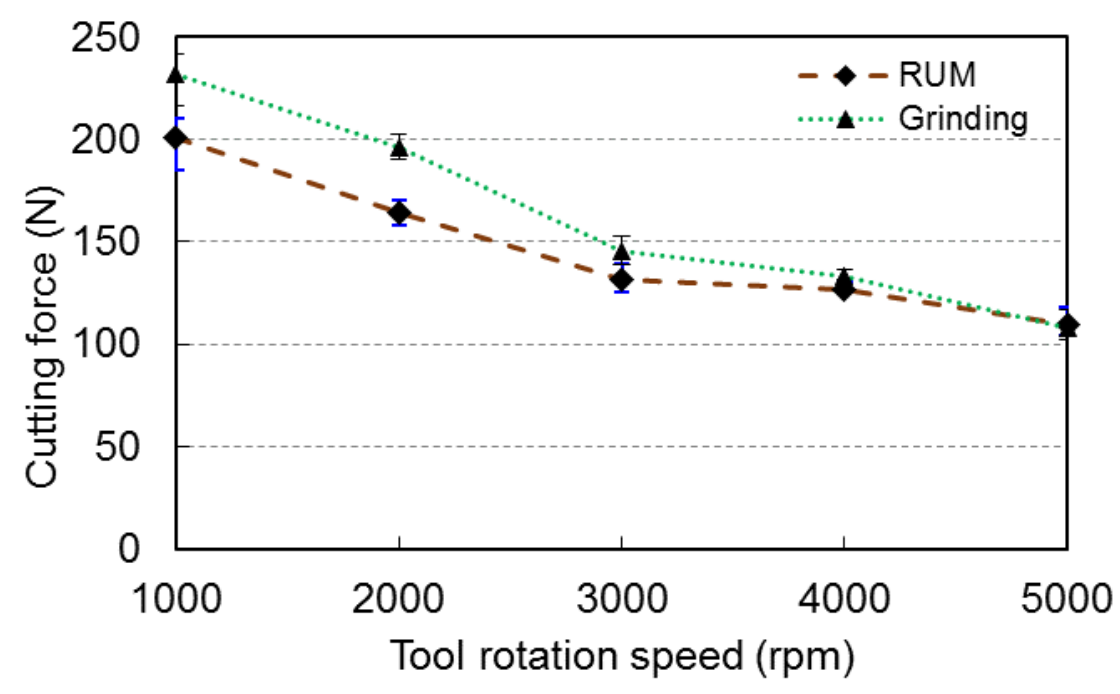

Figure 7. Cutting force comparison between RUM and grinding when tool rotation speed changed.

For all different levels of tool rotation speed, cutting forces in RUM were always lower than those in grinding. The difference in cutting force between these two methods became smaller as tool rotation speed increased, and difference almost disappeared when tool rotation speed 
reached to $5000 \mathrm{rpm}$. During RUM process, high frequency ultrasonic vibration was applied on the cutting tool making the abrasive grains penetrated into the workpiece. With the increase of tool rotation speed to $5000 \mathrm{rpm}$, the penetration depth was decreased to a quite small level and effective cutting distance was increased remarkably, which would significantly reduce or eliminate the influences of ultrasonic vibrations on the cutting force. The changes of cutting force in RUM and grinding within the range of tool rotation speed were $90 \mathrm{~N}$ and $125 \mathrm{~N}$, respectively.

Figure 8 shows a comparison of cutting force between RUM and grinding under different settings of feed rate. As feed rate increased from 0.1 to $0.8 \mathrm{~mm} / \mathrm{s}$, cutting force for both RUM and grinding increased. According to Equation 1, material removal rate would increase with the increase of feed rate (h/T in the equation), which was caused by an increased penetration depth of the diamond grain into the workpiece material. With the similar reasons, the interaction force would increase and consequently led to the increase of the cutting force. Cutting force in grinding was higher than that in RUM and the difference between them was nearly the same (about $16 \mathrm{~N}$ ) at almost all levels of feed rate. However, when feed rate was $0.1 \mathrm{~mm} / \mathrm{s}$, cutting forces in both RUM and grinding were nearly the same (about $115 \mathrm{~N}$ ). When feed rate changed from 0.1 to $0.8 \mathrm{~mm} / \mathrm{s}$, the change of cutting force in RUM was $53 \mathrm{~N}$ which was lower than that in grinding $(69 \mathrm{~N})$.

Compared with grinding, RUM led to lower cutting force at all different levels of feed rate. In RUM, $F_{i}$ in RUM was larger than that in grinding in a $1 / f$ period of time. However, $\Delta t$ in RUM was much smaller than that in grinding. Therefore, $F_{i} \cdot \Delta t$ in RUM was smaller than that in grinding, resulting in lower cutting force in RUM according to Equation 2. 


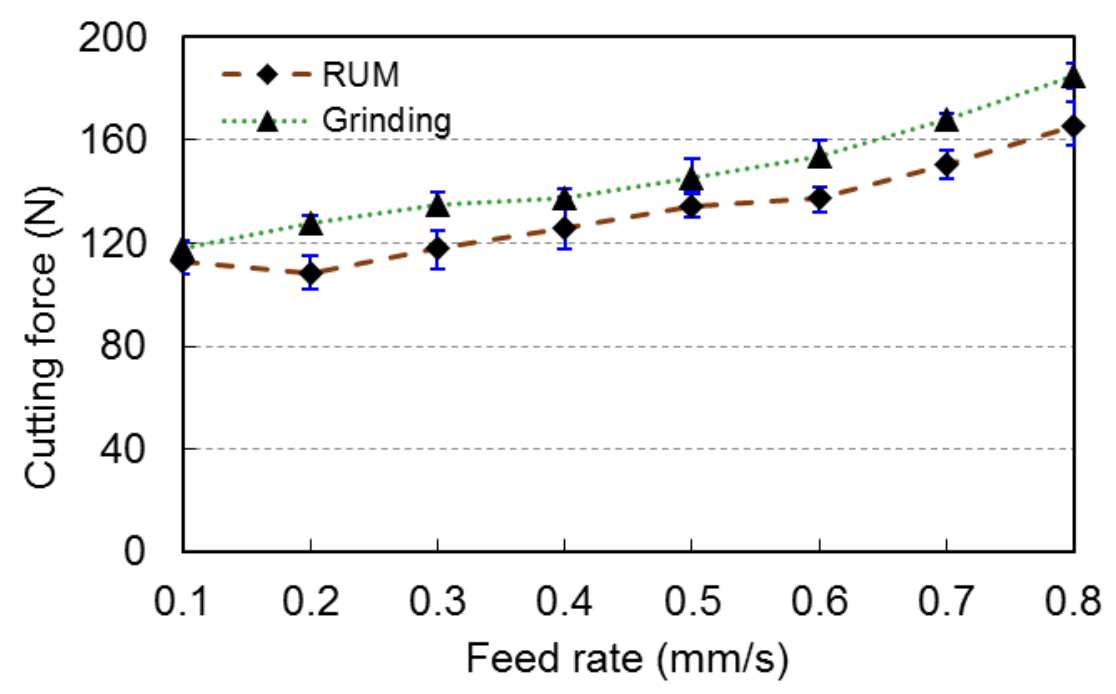

Figure 8. Cutting force comparison between RUM and grinding when feed rate changed.

\subsection{Effects on torque}

Figure 9 shows a torque comparison between RUM and grinding at different levels of tool rotation speed. For both RUM and grinding, torque decreased when tool rotation speed increased. Using grinding led to larger torque than using RUM at all levels of tool rotation speed. The difference in torque between RUM and grinding decreased remarkably (from 0.43 to $0.06 \mathrm{~N} \cdot \mathrm{m}$ ), when tool rotation speed increased from 1000 to $5000 \mathrm{rpm}$. With the increase of tool rotation speed, the change of torque in grinding was about $0.6 \mathrm{~N} \cdot \mathrm{m}$, which was larger than that in RUM (less than $0.2 \mathrm{~N} \cdot \mathrm{m}$ ).

A comparison of torque between the two types of drilling methods when feed rate changed is shown in Figure 10. As feed rate increased from 0.1 to $0.8 \mathrm{~mm} / \mathrm{s}$, torque increased for both types of methods. At all levels of feed rate, torque in grinding was larger than that in RUM. The difference in torque between RUM and grinding was very small (about $0.03 \mathrm{~N} \cdot \mathrm{m}$ ) when feed rate was smaller than $0.3 \mathrm{~mm} / \mathrm{s}$. It became larger when feed rate increased from 0.3 to $0.6 \mathrm{~mm} / \mathrm{s}$, and remained almost constant (about $0.16 \mathrm{~N} \cdot \mathrm{m}$ ) when feed rate was larger than $0.6 \mathrm{~mm} / \mathrm{s}$. Within the 
range of feed rate, the change of torque in grinding was $0.3 \mathrm{~N} \cdot \mathrm{m}$, higher than that in RUM $(0.18$ $\mathrm{N} \cdot \mathrm{m})$.

The trends of effects of input variables on torque were similar to those on cutting force. As torque was correlative to cutting force during RUM and grinding, same explanations for the trends and comparisons of the cutting force between these two methods can be sued for those of torque.

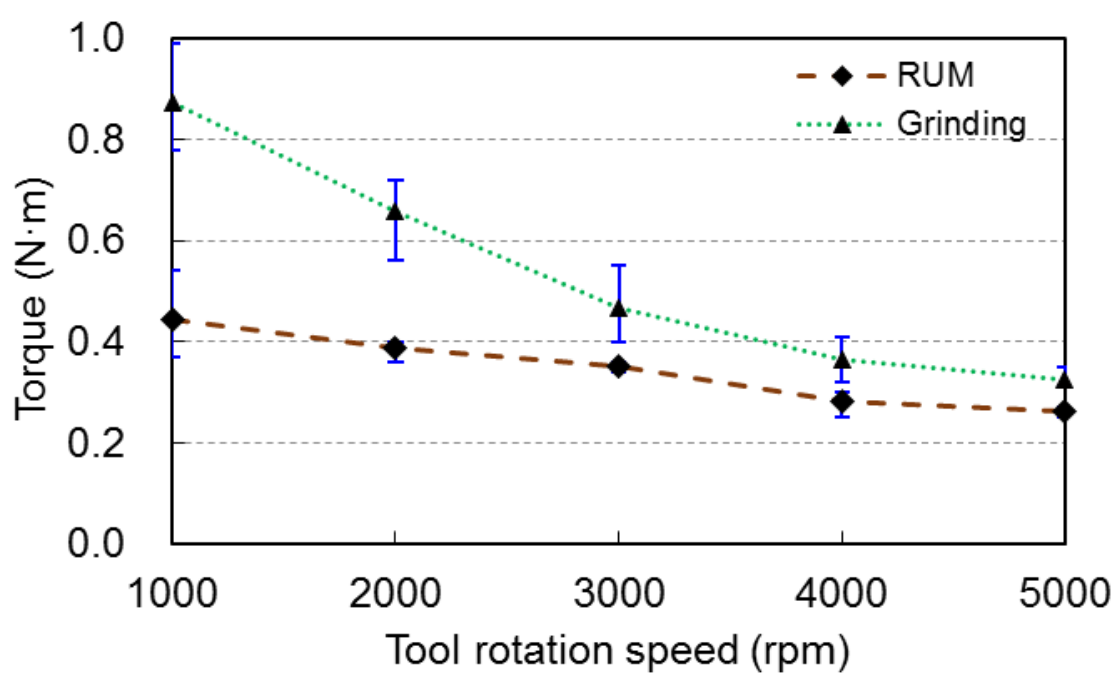

Figure 9. Torque comparison between RUM and grinding when tool rotation speed changed.

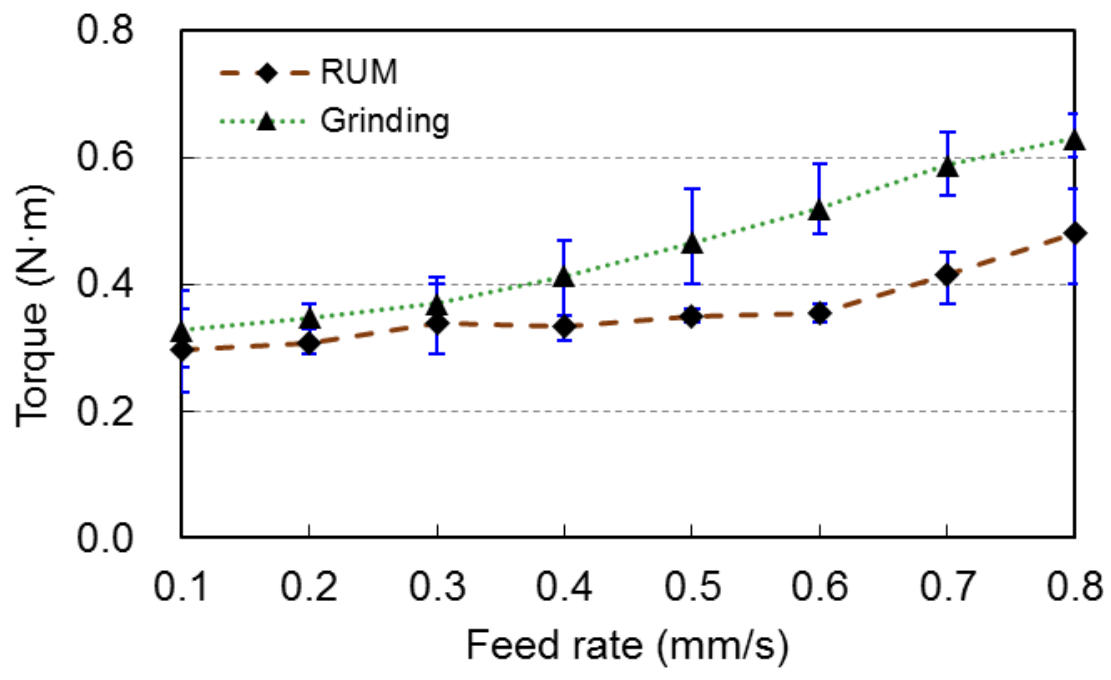

Figure 10. Torque comparison between RUM and grinding when feed rate changed. 


\subsection{Effects on surface roughness}

A comparison of surface roughness between RUM and grinding at different levels of tool rotation speed is shown in Figure 11. For both RUM and grinding, surface roughness decreased when tool rotation speed increased. With the increase of tool rotation speed, the machining interactions between cutting tool and workpiece within a certain period of time became more frequent, so that more convex materials could be removed by their further interaction with cutting tool. With this reason, the surface of the hole could be ground with lower surface roughness. Surface roughness of the hole generated by grinding was lower than that generated by RUM when tool rotation speed was $1000 \mathrm{rpm}$. When tool rotation speed increased from 2000 to $5000 \mathrm{rpm}$, using grinding led to higher surface roughness than using RUM. The difference in surface roughness between RUM and grinding was very small. Within the range of tool rotation speed, the change of surface roughness in RUM was $1 \mu \mathrm{m}$, larger than that in grinding $(0.6 \mu \mathrm{m})$.

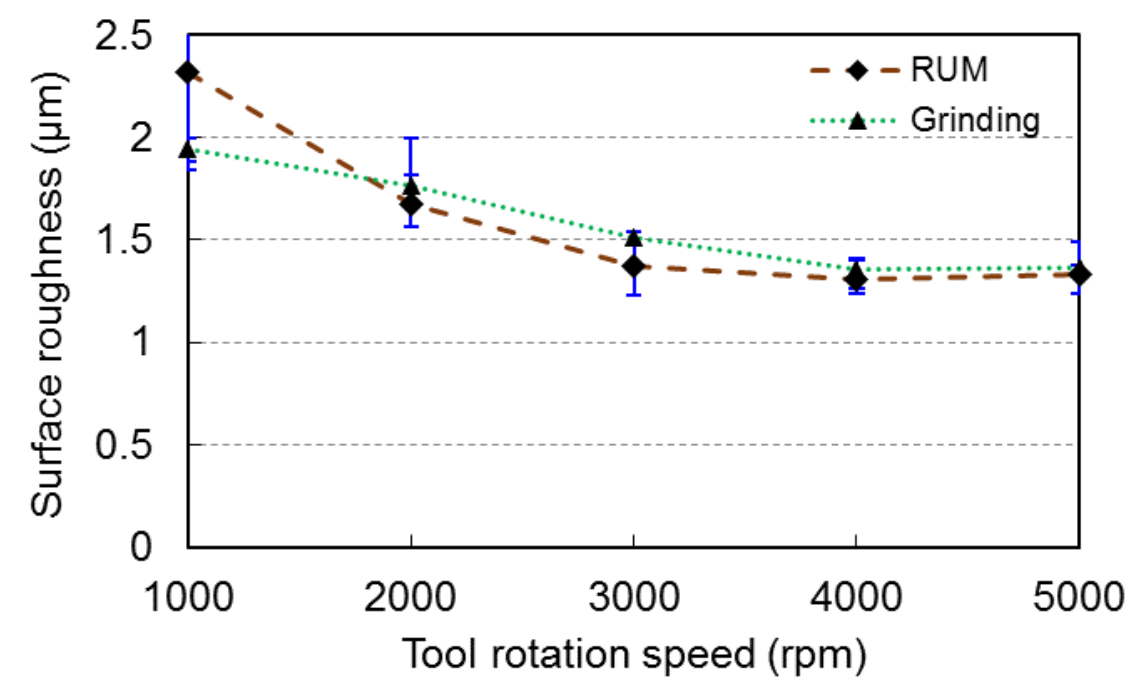

Figure 11. Surface roughness comparison between RUM and grinding when tool rotation speed changed.

Figure 12 shows a comparison of surface roughness between the two types of drilling methods when feed rate changed. For both RUM and grinding, surface roughness increased with 
the increase of feed rate. As the cutting time decreased with the increase of feed rate in the same hole depth, the interaction time between hole surface and cutting tool decreased accordingly, leading to higher surface roughness. There was no obvious difference in surface roughness between RUM and grinding at different settings of feed rate. The changes in surface roughness for both RUM and grinding were about $0.65 \mu \mathrm{m}$.

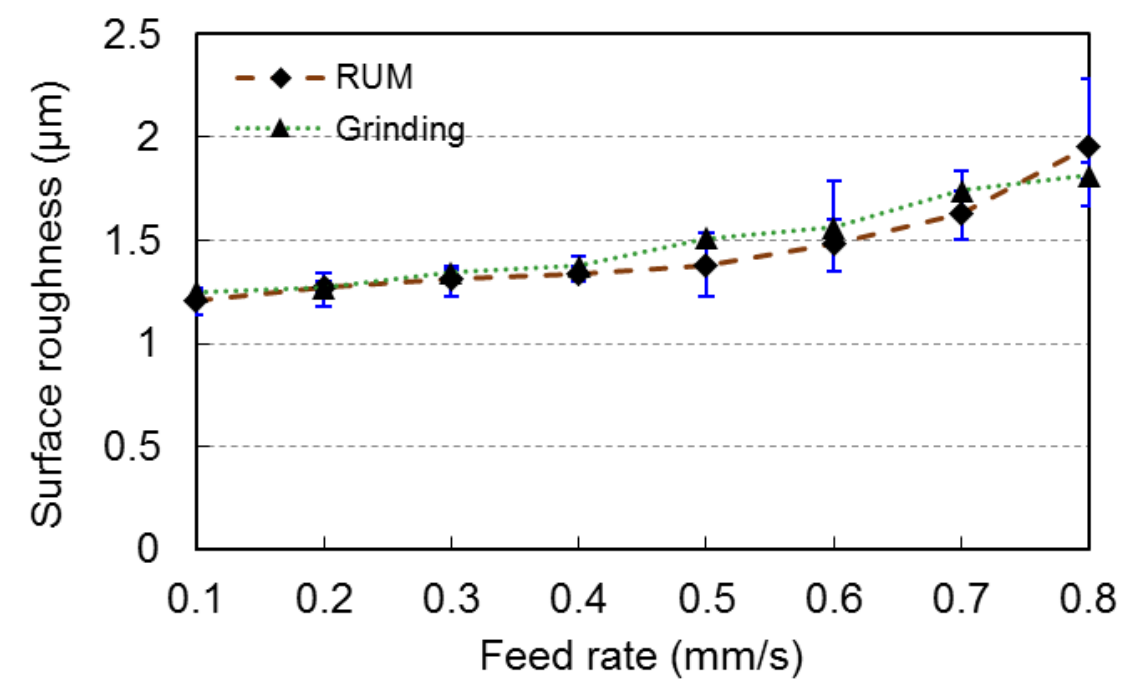

Figure 12. Surface roughness comparison between RUM and grinding when feed rate changed.

\subsection{Effects on hole diameter}

Hole diameter is one of the parameters to evaluate hole drilling consistency. Figure 13 compares the hole diameter between RUM and grinding at different levels of tool rotation speed. It can be seen that, when tool rotation speed increased, hole diameter decreased for both drilling methods. The possible reason is that with the increase of tool rotation speed, the roundness of tool rotation decreased, leading to a lower horizontal oscillation. As a result, hole diameter decreased. When tool rotation speed was low (1000 rpm), hole diameter in grinding was larger than that in RUM. However, at a higher tool rotation speed of $5000 \mathrm{rpm}$, hole diameter in RUM was larger than that in grinding. Hole diameters in both RUM and grinding were almost the same at other settings of 
tool rotation speed. The change in hole diameter for RUM $(0.023 \mathrm{~mm})$ was smaller than that for grinding $(0.038 \mathrm{~mm})$.

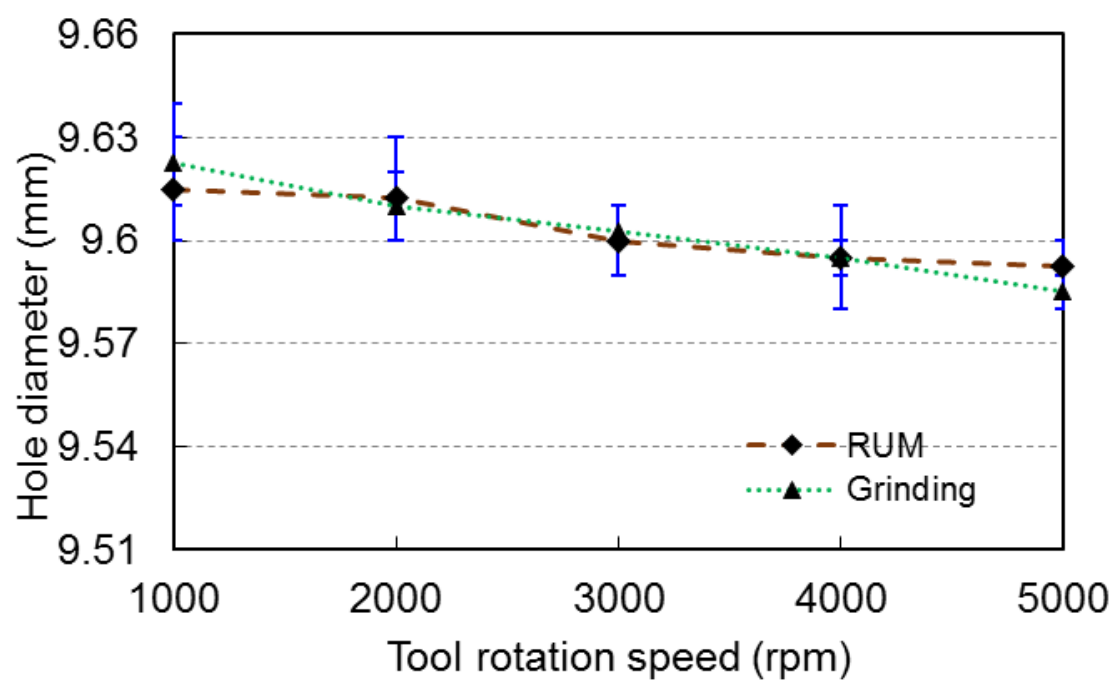

Figure 13. Hole diameter comparison between RUM and grinding when tool rotation speed changed.

Figure 14 shows a comparison of hole diameter between the two types of methods when feed rate changed. For both RUM and grinding, hole diameter decreased with the increase of feed rate. The cutting time decreased with the increase of feed rate so that materials removed from the cylindrical surface of the hole were less, resulting in decreased hole diameter. When feed rate was lower than $0.5 \mathrm{~mm} / \mathrm{s}$, hole diameter in grinding was larger than that in RUM. However, using grinding led to smaller hole diameter than using RUM when feed rate exceeded $0.5 \mathrm{~mm} / \mathrm{s}$. The change in hole diameter for RUM was $0.028 \mathrm{~mm}$ which is smaller than that for grinding $(0.06 \mathrm{~mm})$. 


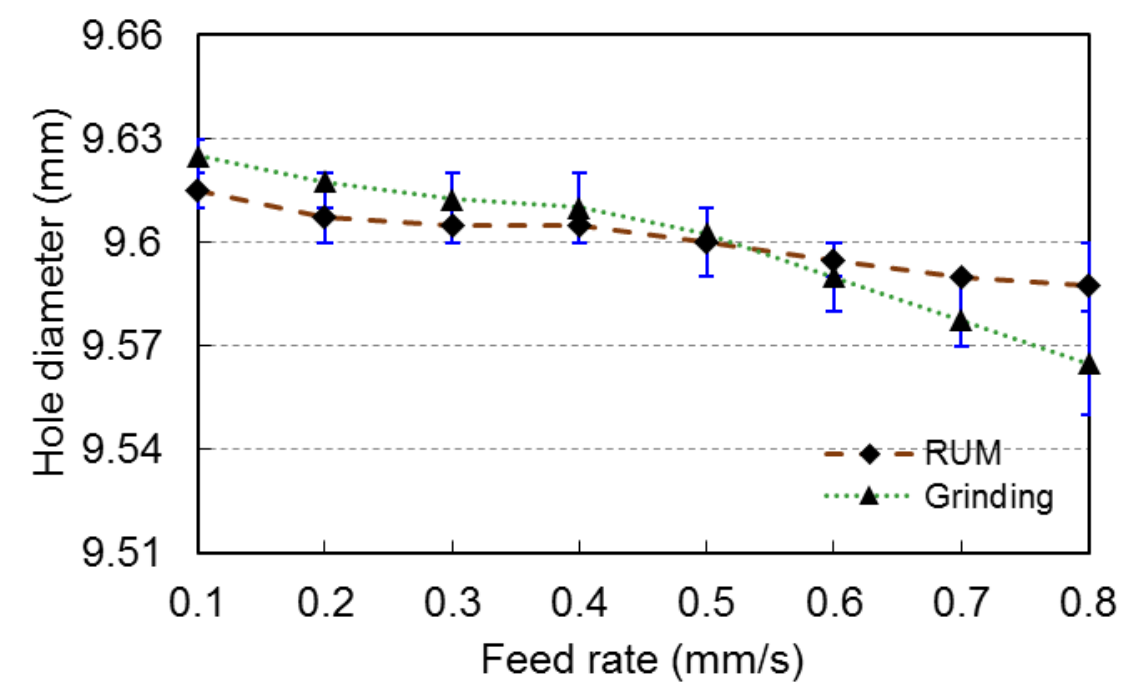

Figure 14. Hole diameter comparison between RUM and grinding when feed rate changed.

\subsection{Effects on material removal rate}

A comparison of MRR between RUM and grinding at different settings of tool rotation speed is shown in Figure 15. It can be seen that with the increase of tool rotation speed, MRR in grinding decreased and MRR in RUM increased gently and then decreased. MRR in RUM was higher than that in grinding at high levels of tool rotation speed (4000 to $5000 \mathrm{rpm}$ ). When tool rotation speed was at low levels (1000 to $3000 \mathrm{rpm}$ ), MRRs in both RUM and grinding were about the same. The change of MRR in grinding $\left(0.05 \mathrm{~mm}^{3} / \mathrm{s}\right)$ was larger than that in RUM $\left(0.02 \mathrm{~mm}^{3} / \mathrm{s}\right)$ within the whole range of tool rotation speed.

Figure 16 shows a MRR comparison between RUM and grinding when feed rate changed. For both RUM and grinding, MRR increased linearly with the increase of feed rate. Both methods had no obvious difference in MRR at all levels of feed rate. 


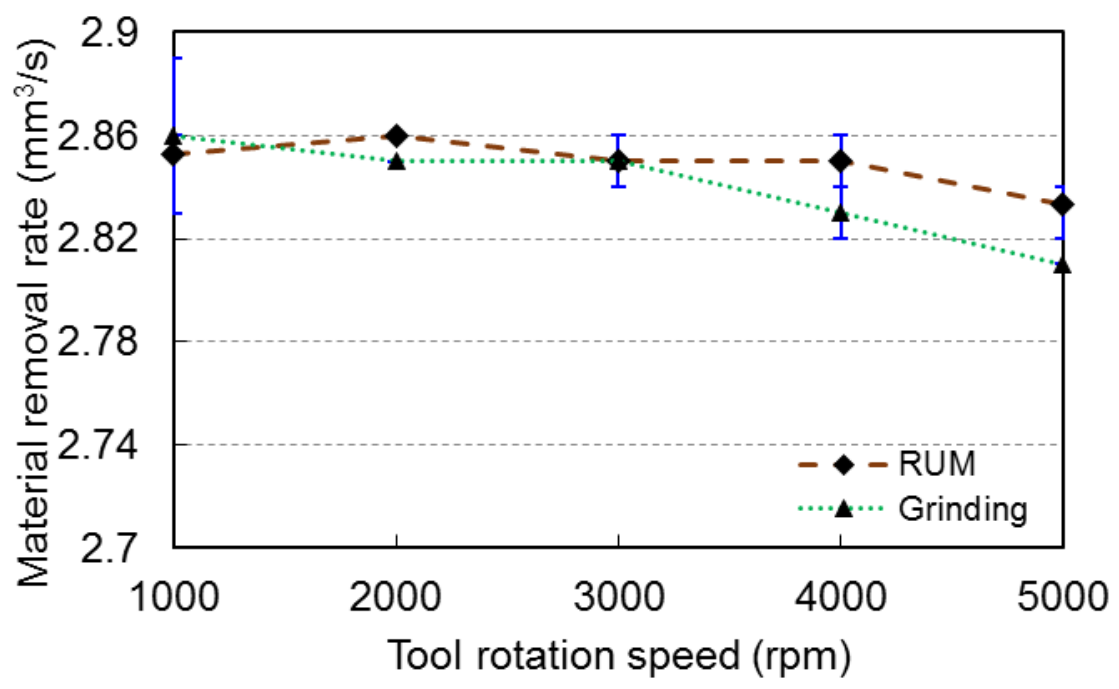

Figure 15. Material removal rate comparison between RUM and grinding when tool rotation speed changed.

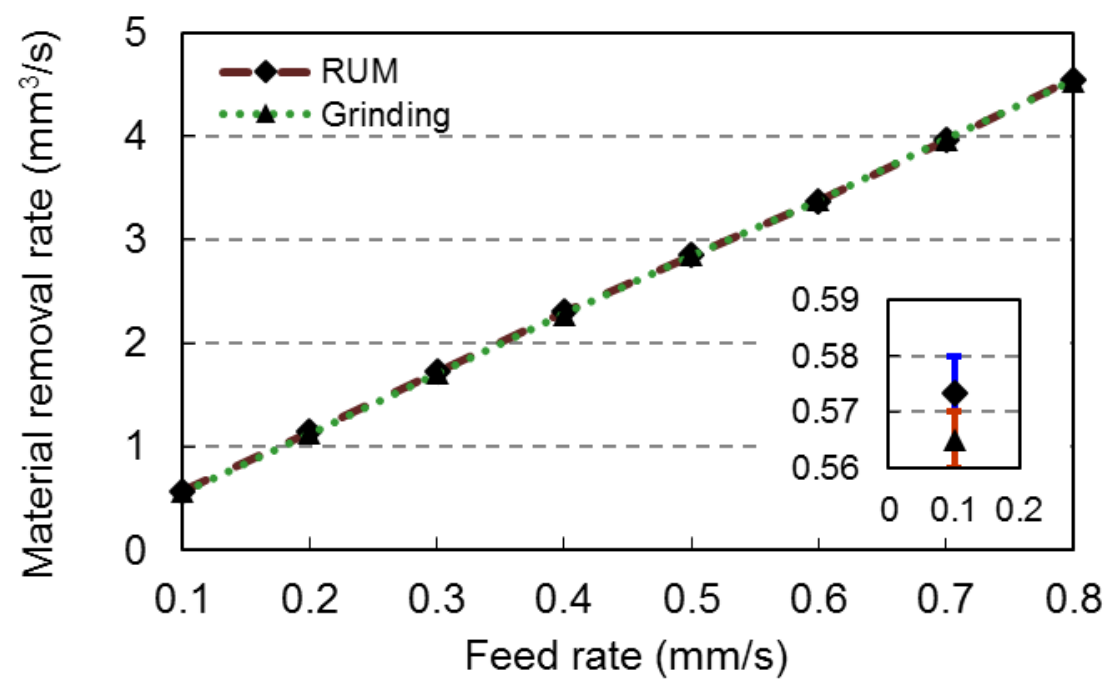

Figure 16. Material removal rate comparison between RUM and grinding when feed rate changed.

\section{Conclusions}

This paper reported the comparisons between rotary ultrasonic machining (RUM) and grinding of CFRP for the first time. Five output variables were compared, including cutting force, torque, surface roughness, hole diameter, and material removal rate (MRR). The conclusions are drawn 
as follows:

(a) Cutting force, torque, surface roughness, and hole diameter decreased for both RUM and grinding with the increase of tool rotation speed. MRR in grinding decreased and MRR in RUM increased gently first, then decreased when tool rotation speed increased. With the increase of feed rate, cutting force, torque, surface roughness, and MRR increased, and hole diameter decreased, for both RUM and grinding.

(b) Almost all the cutting force and torque in grinding were higher than those in RUM for both tool rotation speed and feed rate. In other words, equal MRR generated higher cutting force and torque in grinding than in RUM.

(c) Surface roughness in grinding was higher than that in RUM under almost all conditions. This indicated that using grinding led to worse surface roughness.

(d) The change of hole diameter in grinding was larger than that in RUM. This revealed that the hole size consistency was worse in grinding.

(e) RUM had higher material removal rate than grinding at higher levels of tool rotation speed. MRR values in both RUM and grinding were nearly equal at all levels of feed rate and lower levels of tool rotation speed.

Compared with grinding, RUM performs better in drilling of CFRP, including lower cutting force, lower torque, and better surface roughness. Compared with grinding machine, RUM machine required ultrasonic generation system and special tools (without welding joints). Such differences increased the investment of machine itself. However, the investment cost of RUM process mainly consisted of energy cost and tool cost. Tool cost of RUM was lower than that of grinding due to less tool wear resulting from lower cutting force and torque during RUM of CFRP. With the same energy cost, the total investment cost of RUM process would be decreased. 


\section{Acknowledgements}

The work was partially supported by National Science Foundation through award CMMI0900462.

\section{References}

[1] Abrate, S., and D.A. Walton, 1992, Machining of composite materials. Part I: Traditional methods, Composites Manufacturing, 3(2), pp. 75-83.

[2] Biermann, D., and Feldhoff, M., 2012, Abrasive points for drill grinding of carbon fibre reinforced thermoset. CIRP Annals-Manufacturing Technology, 61(1), pp. 299-302.

[3] Boeing Co. website, 2006, Boeing 787 from the ground up, http://www.boeing.com/commercial/aeromagazine/articles/qtr_4_06/article_04_2.html.

[4] Boeing Co. website, 2014, 787 Dreamliner Program Fact Sheet, http://www.boeing.com/commercial/787family/programfacts.html.

[5] Chung, D.D.L., 2010, Composite Materials Science and Applications, 2nd edition, Springer London Ltd, London, UK.

[6] Cong, W.L., Pei, Z.J., and Treadwell, C., 2014a, Preliminary study on rotary ultrasonic machining of CFRP/Ti stacks, Ultrasonics, 54(6), pp. 1594-1602.

[7] Cong, W.L., Pei, Z.J., Sun, X., and Zhang, C.L., 2014b, Rotary ultrasonic machining of CFRP: A mechanistic predictive model for cutting force, Ultrasonics, 54(2), pp. 663-675.

[8] Cong, W.L., Pei, Z.J., Deines, T.W., Liu, D.F., and Treadwell, C., 2013, Rotary ultrasonic machining of CFRP/Ti stacks using variable feedrate. Composites Part B: Engineering, 52, pp.303-310.

[9] Cong, W.L., Pei, Z.J., Feng, Q., Deines, T.W., and Treadwell, C., 2012a, Rotary ultrasonic machining of CFRP: a comparison with twist drilling, Journal of Reinforced Plastics and 
Composite, 31(5), pp. 313-321.

[10] Cong, W.L., Pei, Z.J., Deines, T.W., Srivastava, A., Riley, L., and Treadwell, C., 2012b, Rotary ultrasonic machining of CFRP composites: A study on power consumption, Ultrasonics, 52(8), pp. 1030-1037.

[11]Cong, W.L., Feng, Q., Pei, Z.J., Deines, T.W., and Treadwell, C., 2011, Dry machining of carbon fiber reinforced plastic composite by rotary ultrasonic machining: effects of machining variables, Proceedings of the ASME 2011 International Manufacturing Science and Engineering Conference (MSEC 2011), Corvallis, OR, USA, June 13-17.

[12] Davim, J.P., and Reis P., 2003, Drilling carbon fiber reinforced plastics manufactured by autoclave-experimental and statistical study, Materials and Design, 24(5), pp. 315-324.

[13] Feng, Q., Cong, W.L., Pei, Z.J., and Ren, C.Z., 2012, Rotary ultrasonic machining of carbon fiber-reinforced polymer: feasibility study, Machining Science and Technology, 16(3), pp. 380-398.

[14] Gay, D., Hoa, S.V., and Tsai, S.W., 2003, Composite Materials Design and Applications, 4th edition, CRC press, Boca Raton, FL, USA.

[15] Guu, Y.H., Hocheng, H., Tai, N.H., and Liu, S.Y., 2001, Effect of electrical discharge machining on the characteristics of carbon fiber reinforced carbon composites, Journal of Materials Science, 36(8), pp. 2037-2043.

[16] IndustryWeek. website, 2012, How Composites are Strengthening the Aviation Industry, authored by Robert Yancey, http://www.industryweek.com/none/how-composites-arestrengthening-aviation-industry.

[17] Kalla, D.K., Zhang, B., Asmatulu, R., and Dhanasekaran, P.S., 2012, Current research trends in abrasive waterjet machining of fiber reinforced composites, Materials Science Forum, 
713, pp. 37-42.

[18] Kinet, D., Mégret, P., Goossen, K.W., et al., 2014, Fiber Bragg Grating Sensors toward Structural Health Monitoring in Composite Materials: Challenges and Solutions, Sensors, 14(4), pp. 7394-7419.

[19] Li, Z.C., Pei, Z.J., Sisco, T., Micale, A.C. and Treadwell, C., 2007, Experimental study on rotary ultrasonic machining of graphite/epoxy panel, Proceedings of the ASPE 2007 Spring Topical Meeting on Vibration Assisted Machining Technology, Chapel Hill, NC, April 16-17, pp. 52-57.

[20] Liu, D., Cong, W.L., Pei, Z.J., and Tang, Y.J., 2012, A cutting force model for rotary ultrasonic machining of brittle materials, International Journal of Machine Tools and Manufacture, 52(1), pp. 77-84.

[21] Mallick, P.K., 1997, Composite Engineering Handbook, CRC Press, Marcel Dekker Inc., New York, NY, USA.

[22] Mazumdar, S. 2001, Composites manufacturing: materials, product, and process engineering, CRC Press, Marcel Dekker Inc., New York, NY, USA.

[23] Park, K.Y., Choi, J.H., and Lee, D.G., 1995, Delamination-free and high efficiency drilling of carbon fiber reinforced plastics, Journal of Composite Materials, 29(15), pp. 1988-2002.

[24] Pei, Z.J., Prabhakar, D., Ferreira, P.M., and Haselkorn, M., 1995, A mechanistic approach to the prediction of material removal rates in rotary ultrasonic machining, Journal of Engineering for Industry, 117(2), pp. 142-151.

[25] Quilter, A., 2001, Composites in aerospace applications. IHS White Paper, 444, pp. 1-3.

[26] Ramulu, M., Branson, T., and Kim, D., 2001, A study on the drilling of composite and titanium stacks, Composite Structure, 54(1), pp. 67-77. 
[27] Sadat, A.B., 1995, Delamination and other types of damage of graphite/epoxy composite caused by machining, Applied Mechanics Division and the Materials Division: Machining of Advanced Materials, June 28-30, Los Angeles, CA, pp. 41-52.

[28] Soo, S.L., Shyha, I.S., Barnett, T., Aspinwall, D.K., and Sim, W.M., 2012, Grinding performance and workpiece integrity when superabrasive edge routing carbon fibre reinforced plastic (CFRP) composites, CIRP Annals-Manufacturing Technology, 61(1), pp. $295-298$.

[29] Stock, J., Zaeh, M.F., and Conrad, M., 2012, Remote laser cutting of CFRP: improvements in the cut surface, Physics Procedia, 39, pp. 161-170.

[30] Strong, A. B., 2008, Fundamentals of composites manufacturing: materials, methods and applications, 2nd edition, SME.

[31] Tong, L., Mouritz, A.P., and Bannister, M.K., 2002, 3D Fibre Reinforced Polymer Composites, Elsevier Science Ltd, Oxford, UK.

[32] Tsao, C.C. and Hocheng, H., 2004, Taguchi analysis of delamination associated with various drill bits in drilling of composite material, International Journal of Machine Tools and Manufacture, 44(10), pp. 1085-1090.

[33] Wang, X., Wang, L.J., and Tao, J.P., 2004, Investigation on thrust in vibration drilling of fiber-reinforced plastics, Journal of Materials Processing Technology, 148(2), pp. 239-244. 